\title{
A DEMOCRATIZAÇÃO DO ACESSO AO ENSINO SUPERIOR NO BRASIL É UM INSTRUMENTO DE JUSTIÇA SOCIAL? POSSIBILIDADES E DESAFIOS NA FORMAÇÃO DE PROFESSORES
}

\author{
IS DEMOCRATIZATION OF ACCESS TO HIGHER EDUCATION IN \\ BRAZIL AN INSTRUMENT OF SOCIAL JUSTICE? POSSIBILITIES AND \\ CHALLENGES IN TEACHER TRAINING
}

\author{
Renata Meira Veras \\ Doutora, Universidade Federal da Bahia - UFBA. \\ Salvador, Bahia - Brasil. \\ renata.veras@ufba.br \\ Daiane da Luz Silva \\ Mestre, Universidade Federal da Bahia - UFBA \\ Salvador, Bahia - Brasil. \\ daiane@ufba.br
}

\begin{abstract}
Resumo: As ações afirmativas desempenham papel fundamental no processo de democratização do acesso ao ensino superior no Brasil, principalmente nos cursos de formação inicial de professores que possuem grande representatividade das classes menos favorecidas. Diante disso, este estudo teve como questão: de que maneira os estudantes de licenciatura da Universidade Federal da Bahia percebem sua presença no ensino superior e utilizam os conhecimentos adquiridos nesse espaço como educadores? A partir de uma perspectiva epistêmica decolonial, o objetivo desta pesquisa foi explorar os significados atribuídos pelos estudantes à experiência de estar no ensino superior evidenciando os desafios da justiça social nesse processo inclusivo. O estudo de caso foi o método utilizado, tendo como instrumentos entrevistas realizadas com 74 estudantes. A partir da análise de conteúdo pudemos agrupar seus relatos em três categorias: o perfil socioeconômico e a escolha pelo curso; os atores sociais no engajamento pela educação de qualidade; e a hierarquização dos saberes popular e científico na Universidade. Mais da metade dos estudantes participantes possuem baixa renda familiar; a maioria é negra e estudou em escola pública; destacaram o reconhecimento da justiça social ao ter acesso ao curso em uma instituição federal de ensino superior; a importância da educação para formação do cidadão; a ênfase do autoconhecimento como processo de educação emancipatória; a necessidade de políticas públicas e institucionais que viabilizem a permanência e a conclusão da formação; e, por fim, a falta de reconhecimento dos conhecimentos prévios que poderiam fazer parte da troca profícua de saberes necessários ao processo educativo.
\end{abstract}

Palavras-chave: Democratização do acesso. Formação inicial de professores. Justiça social. Universidade.

\begin{abstract}
Affirmative action's play an essential role in the process of democratizing access to higher education in Brazil, especially in initial teacher education courses, which have a large representation of the less favored classes. Based on this, this study asked: How do undergraduate students at the Universidade Federal da Bahia perceive their presence in higher education and use the knowledge acquired in this space as educators? From a decolonial epistemic perspective, the goal of this research was to explore the meanings attributed by students to the experience of being in higher education highlighting the challenges of social justice in this inclusive process. The case study was the method used, having as instruments interviews and focus groups conducted with 74 students. From the content analy sis we were able to group their reports into three categories: The socioeconomic profile and choice of the course; social actors in the commitment to quality education; and hierarchy of popular and scientific knowledge at the University. More than half of the participating students have a low-income family, most are black and attended public school. Student's reports have demonstrated recognition of social justice by having access to the course at a federal higher education institution; the importance of education for citizen formation; the emphasis of selfknowledge as a process of emancipatory education; the need for public and institutional policies that enable the permanence and completion of training; and, finally, the lack of recognition of prior knowledge that could be part of the fruitful exchange of knowledge necessary for the educational process.
\end{abstract}

Keywords: Democratization of access. Initial teacher education. Social justice. University.

Para citar - (ABNT NBR 6023:2018)

VERAS, Renata Meira; SILVA , Daiane da Luz. A democratização do acesso ao ensino superior no brasil é um instrumento de justiça social? possibilidades e desafios na formação de professores. Eccos - Revista Cientifica, São Paulo, n. 54, p. 1-18, e17325, jul./set. 2020. Disponível em: https://doi.org/10.5585/eccos.n54.17325. 


\section{Introdução}

As mudanças que temos presenciado no Brasil contemporâneo, motivadas pelas novas formas de organização econômica neoliberal, vêm contribuindo para o que se pode denominar de crise institucional nas universidades públicas, resultando em sérias consequências como a destituição da educação enquanto direito social (SANTOS, 2011). Apesar disso, é notório destacar alguns esforços de governos anteriores em prol da democratização do acesso e diminuição da elitização nessas instituições, a exemplo do Exame Nacional do Ensino Médio, da Política de Cotas para o acesso às universidades públicas (implementada oficialmente no Brasil desde 2012, por meio da Lei n. 12.711), dos programas de assistência estudantil e das ações de expansão da educação superior do Governo Federal, entre elas, o Programa de Apoio a Planos de Reestruturação e Expansão das Universidades Federais (REUNI) em 2008.

Especificamente, os programas de ação afirmativa surgiram articulados com movimentos sociais que exigiam mecanismos equitativos no acesso a serviços públicos. Para autores como Almeida Filho et al. (2005), Krishna e Tarasov (2013) e Santos (2011), o ingresso de estudantes por meio de cotas nas universidades proporciona a oportunidade de acesso dos grupos subrepresentados no ambiente acadêmico, o aumento das relações intergrupos sociais (consequentemente a redução da discriminação de renda e raça), e a melhora na formação educacional da sociedade como um todo. Porém, Moelecke (2004) destaca que as políticas de ação afirmativa tensionam tanto os marcos democráticos em relação à igualdade quanto a noção do povo mestiço ainda permeada pelo preconceito no Brasil. Em razão disso, na seara dos debates atuais sobre reforma e expansão, o sistema de ensino superior brasileiro enfrenta o desafio de encontrar soluções que respondam às questões das desigualdades sociais no acesso e permanência às suas instituições.

Os cursos de formação inicial de professores (licenciaturas) desempenham um papel fundamental para compreender essas relações, já que têm a finalidade de contribuir na busca por uma sociedade mais justa, em relações interpessoais, por onde perpassam os sentidos de uma civilização (GATTI, 2013). Essa autora ainda afirma que a educação, por ser um direito humano e bem público, propicia às pessoas reconhecerem e exercerem esses direitos. Sendo assim, o processo educacional passa a ser essencial na compreensão, conscientização, demanda e luta pelos direitos humanos.

Uma maneira de discutir essas questões de desigualdades sociais e igualdade de oportunidade no acesso ao ensino superior é proposta por Sen (2009), que se interessa em 
compreender de que maneira as pessoas valorizam os recursos educacionais disponíveis e de que forma esses recursos podem influenciar o modo de vida de cada um.

Nesse sentido, sustentamos que é necessário dar voz ao grupo que recentemente vem acessando os cursos de formação inicial de professores através das políticas e dos programas de expansão e permanência. Com base nisso, este estudo foi realizado na Universidade Federal da Bahia que pactuou, por meio do REUNI, na expansão dos cursos de licenciatura, principalmente noturno, ofertando $50 \%$ das vagas para estudantes cotistas.

Sendo assim, este estudo teve como questão central: de que maneira os estudantes de licenciatura da Universidade Federal da Bahia percebem sua presença no ensino superior e como utilizam os conhecimentos adquiridos nesse espaço como educadores?

Portanto, apresentamos como objetivo deste estudo explorar os significados atribuídos pelos estudantes à experiência de estar no ensino superior evidenciando os desafios da efetivação da justiça social nesse processo inclusivo.

\section{Justiça social e democratização do acesso ao ensino superior}

O direito à educação básica de qualidade é um direito humano fundamental, que deve, na mesma medida, impulsionar para uma formação superior centrada nos critérios de qualidade e equidade. No entanto, esse direito passou a ser reconhecido, em nível global, a partir da promulgação da Declaração dos Direitos Humanos (DUDH) em 1948, na medida em que vinculou a Educação aos direitos humanos, enquanto meio para a efetivação da igualdade, necessária à tutela da dignidade humana.

Contudo, a igualdade ainda está longe de ser alcançada pela maioria da população brasileira, em face das injustiças sociais que perduram desde o período colonial e que mantêm suas raízes fincadas nas instituições educacionais. Tais injustiças são decorrentes da continuidade dos meios de dominação produzidos pela cultura eurocêntrica e pelo sistema capitalista que aprofundam as desigualdades sociais (SANTOS; MENESES, 2009).

Ademais, o eurocentrismo impõe o colonialismo epistemológico ao definir qual saber é ou não um conhecimento válido e ao marginalizar os saberes advindos dos povos subalternizados (MIGLIEVICH-RIBEIRO; ROMENA JR., 2017). Mignolo (2005, 2008), assumindo uma perspectiva decolonial, argumenta que o conhecimento é produzido geohistoricamente e está geopoliticamente localizado, pois, para além das diferenças coloniais epistemológicas, nega o agenciamento político e epistêmico àquelas pessoas consideradas inferiores, segundo critérios de raça, gênero, sexualidade entre outros (MIGNOLO, 2008). Por 
essa razão, a decolonização do conhecimento é uma perspectiva necessária para dissipar a suposição eurocêntrica de que o conhecimento válido e legítimo deve ser sancionado pelos padrões europeus.

Para Mignolo (2018), a geopolítica do conhecimento surgiu no século XVI como uma atitude colonial ao definirem a língua castelhana na América Latina (Anáhuac e Tawantns uyu) em detrimento da língua nativa, presidindo a crença na superioridade da ciência e do saber ocidental.

Assim, ainda na perspectiva epistêmica decolonial apontadas por Santos e Menezes (2009), torna-se necessário romper com os paradigmas eurocêntricos hegemônicos que permearam a estruturação das sociedades ocidentais nos últimos 500 anos e, por consequência, foram promotores de todas espécie de exclusão, exploração e negação de direitos às culturas e povos considerados subalternos. Por essa razão, a igualdade deve ser compreendida sob a ótica da realidade social, sendo cabal o reconhecimento de direitos que considerem a existência de certas diferenças e a necessidade de um tratamento não igual (BOBBIO, 2004). No campo dos direitos sociais, especialmente no que tange ao direito à educação, isso ocorre com maior evidência, pois na atribuição desses direitos não se pode deixar de levar em conta as diferenças específicas, que são relevantes para distinguir um indivíduo de outro (BOBBIO, 2004).

Amartya Sen (2009), estudioso do desenvolvimento humano, destacou as limitações da perspectiva utilitarista na medida em que, ao se preocupar apenas com a soma total, essa perspectiva não leva em consideração as desigualdades existentes na distribuição do bem-estar coletivo.

Nesse contexto se enquadram as Políticas de Cotas, caracterizadas por ações governamentais direcionadas aos grupos discriminados e historicamente vítimas da exclusão social. Compreende-se que essas ações são necessárias para gerar igualdade de oportunidades, porquanto a ideia é reparar o desvio das contingências na direção da igualdade, tomando por base o princípio da reparação, como um critério de justiça social, sendo que, na aplicação desse princípio, justifica-se destinar maior gasto com a educação do público socialmente menos privilegiado (RAWLS, 1999). Nesses termos se firmou a concepção de Justiça Social, um mecanismo para tornar a convivência em sociedade melhor e mais justa. No contexto brasileiro atual, surge como critério epistêmico na luta pela superação da modernidade colonizadora, rumo à decolonização (SANTOS; MENESES, 2009).

Para Sthephen J. Ball, o conceito de Justiça Social é um conceito inclusivo (MAINARDES; MARCONDES, 2009). Aponta para as diferentes formas em que a opressão se traduz e atua sobre as pessoas, seja pelo gênero, classe, sexualidade ou pelos distintos graus 
de habilidades. Não se restringe somente a segmentos específicos, pois compreende amplas concepções acerca da equidade, justiça e oportunidades.

Entretanto, no contexto educacional brasileiro, frente à expansão do acesso à educação, algumas questões se contrapõem à perspectiva de democratização da educação superior e à igualdade de acessibilidade que se vislumbram nas políticas públicas vigentes, por vezes, sendo entraves para que se concretizem em ações satisfatórias para alcançar mudanças nos padrões de acesso, oportunidade e justiça social (MAINARDES; MARCONDES, 2009). Entre elas, destaca-se a permanência dos estudantes nos espaços universitários, já que não basta ampliar as matrículas e o acesso, mas também dar condições materiais e formativas para que os grupos subrepresentados consigam permanecer no ambiente universitário. Ademais, é necessário superar possíveis defasagens escolares provenientes da educação básica que, em muitos casos, não os prepara para a experiência universitária e por vezes se torna empecilho ao processo de afiliação estudantil e o sucesso educativo. Isso implica também ter uma formação que considere o educando como membro de uma comunidade socialmente coesa e o inclua como parte visível em todos os seus elementos: gênero, cultura, equidade e etnia, entre outros e, desse modo, possa contribuir para transformar as condições sociais, culturais e estruturais institucionais que gerem essas representações, sem subestimar nenhuma delas (MURILLO, 2019, tradução nossa).

Logo, o êxito dessas políticas deveria se traduzir em impactos, tanto nas práticas como nas estruturas, seja no âmbito localizado ou no sistema como um todo (MAINARDES; MARCONDES, 2009). Além disso, não se pode garantir que apenas ampliando o acesso às universidades está se ampliando o direito a uma formação em educação superior de qualidade e equânime.

Para Paula (2006), sem ações complementares que visem à assistência e ao apoio acadêmico aos estudantes, procura-se resolver a dificuldade do acesso, mas não a sua permanência. Atrelada à expansão do acesso às universidades deve haver "um investimento maciço do governo na melhoria da qualidade do ensino público [...] dando-lhes uma base concreta para 'competir' com os filhos das elites e das classes médias" (PAULA, 2006, p. 143) e, portanto, transduzir a justiça social.

Entre os investimentos públicos de relevância social está a formação inicial e continuada dos professores. Nesse quesito, Diniz-Pereira e Soares (2019) defendem que o acesso dos estudantes socialmente vulneráveis ao ensino superior, especificamente, nas licenciaturas, contribui para a transformação social, pois eles compreendem melhor as injustiças sociais e podem colaborar com a efetivação de ações contra as desigualdades presentes na sociedade. Para Zeichner (2008), o desenvolvimento de profissionais docentes vinculados à luta por justiça 
social, leva à diminuição das lacunas na qualidade da educação de estudantes de diferentes perfis, em nível local e global.

Esse acesso também é uma conquista advinda por meio de várias lutas políticas travadas por aqueles que sempre estiveram à margem das benesses sociais, já que o ambiente universitário é historicamente um espaço ocupado pelas elites. Portanto, uma formação para a justiça social perpassa também pela garantia de qualidade dos cursos dedicados à preparação para o magistério e da adoção de estratégias de formação dignas para esses profissionais.

\section{Metodologia}

Trata-se de um estudo de caso, com abordagem qualiquantitativa, por meio de narrativas orais, obtidas por meio de entrevistas semiestruturadas. Optou-se pelo estudo de caso devido à relevância de compreender as características únicas da problemática em uma universidade pública da Bahia, desvelando as potencialidades e demandas próprias desse espaço com relação ao objeto em análise (MORGADO, 2018).

A pesquisa foi realizada no campus da Universidade Federal da Bahia. Os estudantes foram escolhidos aleatoriamente nas dependências das faculdades e institutos que abrigam os cursos de licenciatura. Eram estudantes matriculados entre o $2^{\circ}$ e $10^{\circ}$ semestres dos cursos de licenciatura. Após consulta sobre a participação voluntária no estudo, os estudantes assinaram o Termo de Consentimento Livre e Esclarecido (TCLE) e se dispuseram a dar depoimento acerca de suas percepções sobre a formação para o magistério.

Contribuíram com esse estudo 74 estudantes. Destes, 29 participaram de entrevistas grupais e 45 estudantes foram entrevistados individualmente. Foram 10 participantes do curso de Pedagogia, 1 de Teatro, 17 de Letras, 3 de Dança, 7 de História, 10 de Geografia, 6 de Biologia, 8 de Física, 2 de Ciências Naturais, 5 de Química, 1 de Ciências Sociais, 3 de Matemática e 1 de Computação. Desses estudantes, 29 estavam matriculados no turno noturno e 45 no diurno. O método de saturação das respostas foi a técnica utilizada para elaborar o banco de dados.

Por meio de tópicos previamente construídos e validados em teste piloto, foram realizadas as entrevistas e os grupos focais. Além de questões sociodemográficas, o roteiro da entrevista versou acerca da motivação para cursar licenciatura, a avaliação acerca da formação docente e as perspectivas futuras de trabalho. As entrevistas tiveram duração média de 20 minutos e as entrevistas grupais de 40 minutos. 
Por conter dados estruturados e não estruturados, a análise de dados se deu em duas etapas. Na primeira etapa a análise se concentrou nos dados sociodemográficos, sendo criado um banco de dados no software Microsoft Excel versão 2013 com o intuito de organizar os dados em tabelas e descrevê-los com o uso de proporções.

Na segunda etapa, as falas dos estudantes foram transcritas no Microsoft Word versão 2013 e analisadas à luz da Análise de Conteúdo (AC), a partir da sistematização proposta por Bardin (2016). O método se constitui por três fases, a saber: (1) a pré-análise; (2) a exploração do material e o (3) tratamento dos resultados e interpretação. Em cada etapa há um processo cauteloso e exaustivo de organização e discussão dos dados com o problema de pesquisa e a teoria adotada.

Optou-se pela AC categorial temática, que busca situar o tema como definição central, como também descobrir a frequência de aparição dos núcleos de sentido (BARDIN, 2016). Após a transcrição das entrevistas e leitura exaustiva das mesmas, entendendo a pré-análise como momento crucial para uma rigorosa categorização temática, iniciou-se a identificação e organização dos temas emergentes nas entrevistas.

O estudo foi aprovado pelo Comitê de Ética em Pesquisa da Escola de Enfermagem da UFBA (CAAE: 31687314.0.0000.5531).

\section{Resultados}

A fim de melhor atender aos objetivos propostos nesse estudo, assumiu-se a necessidade de apresentar os resultados em três categorias que foram criadas com base nos dados coletados. As categorias identificadas foram nomeadas: 1. O estudante de licenciatura da UFBA: perfil socioeconômico e a escolha pelo curso; 2. Atores sociais no engajamento pela educação de qualidade no Brasil; 3. A hierarquização dos saberes popular e científico na Universidade.

1 O estudante de licenciatura da UFBA: perfil socioeconômico e a escolha pelo curso

A partir da coleta de dados foi possível identificar que: 44 (59\%) dos estudantes entrevistados recebem renda familiar entre 1 e 3 salários mínimos; 23 (31\%) entre 4 e 6 salários mínimos e apenas 7 (9\%) declararam renda familiar acima de 7 salários mínimos (Figura 1). Além disso, 12 (16,4\%) afirmaram receber assistência estudantil (Figura 2). 
Figura 1 - Renda familiar dos estudantes

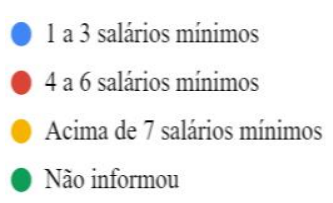

Fonte: Elaborado pelas autoras (2020).

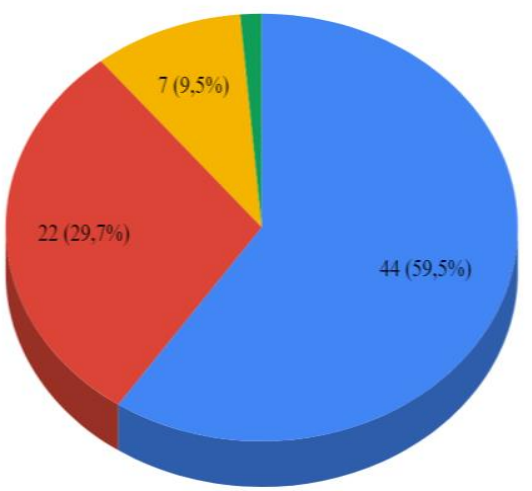

Figura 2 - Assistência estudantil

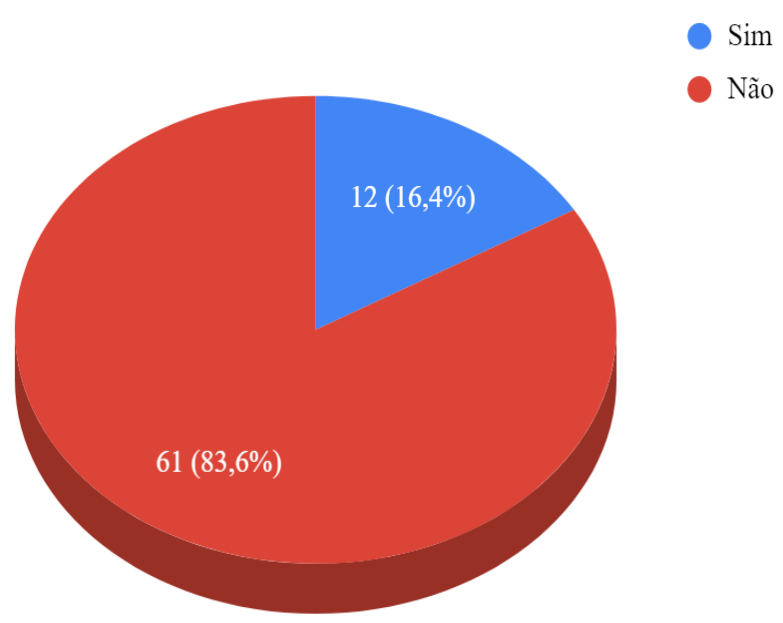

Fonte: elaborado pelas autoras (2020).

Esses dados corroboram o último relatório divulgado em outubro de 2018 pelo Instituto Nacional de Estudos e Pesquisas Educacionais Anísio Teixeira (INEP), referente ao Exame Nacional de Desempenho dos Estudantes (ENADE) 2017. Nesse relatório, os dados sociodemográficos dos estudantes de licenciatura em 2017, indicaram que 66,6\% deles tinham renda familiar inferior a 3 salários mínimos; $31 \%$ não possuem renda e dependem de auxílio financeiro governamental ou de familiares e afins; $26,2 \%$ possuem renda, mas são responsáveis pelo sustento da família (INEP, 2018).

Um estudo realizado por Lopes (2017), com base nos dados do ENADE (2009-2010), identificou que estudantes oriundos de classe socioeconômica desfavorecida e, principalmente, os que obtiveram acesso ao ensino superior por meio das Políticas de Cotas possuíam notas no Exame do Ensino Médio (ENEM) inferior em comparação com os de classes alta e média e 
tendem a ingressar em cursos de nível superior com menor prestígio social. Por consequência, escolhem carreiras menos remuneradas e pouco privilegiadas. Entre essas está a carreira docente, como verificado em algumas falas, cujas poucas perspectivas de crescimento profissional e condições de trabalho refletem o modo como o Estado gere a educação (LAPO; BUENO, 2003).

Eu na verdade queria engenharia civil. Não consegui... e o curso que eu consegui passar foi matemática e tô aqui, nessa vida... Escolhi matemática, porque sempre gostei de cálculo e números (Estudante 59, Matemática, noturno)

Eu pensei que o bacharelado tinha mais oportunidade, mas quando eu entrei no curso percebi que licenciatura era mais fácil de ingressar logo no mercado do que o bacharelado. (Estudante 23, Física, diurno)

Escolhi Letras com licenciatura mais pela ideia de ter um emprego relativamente mais garantido assim que saís se da universidade. Mas desde o início do Ensino Médio eu já pensava em ser professor, independente assim de ter escolhido por pensar no dinheiro (Estudante 46, Letras, noturno).

Em muitos casos, a escolha do curso de licenciatura é a última opção de estudantes que obtiveram menor desempenho nos processos de seleção (LIBÂNEO, 2011). Reflexo também da baixa qualidade dos processos de formação anteriores (predominantemente públicos) ao ingresso nos cursos de formação docente.

Há que considerar também o processo histórico de exclusão e de marginalização de uma parcela significativa de pessoas negras, indígenas e pardas que, na mesma proporção, carecem de ações educacionais inclusivas que the possibilitem não somente $\mathrm{o}$ acesso, mas a permanência. Nesse aspecto, pode-se perceber que na UFBA há uma prevalência de estudantes de licenciatura autodeclarados pardos e negros (78\% dos entrevistados) (Figura 3) e do total de participantes $37,8 \%$ se declararam cotistas, sendo que destes apenas 6 recebem algum tipo de assistência estudantil.

Figura 3 - Autodeclaração étnico-racial

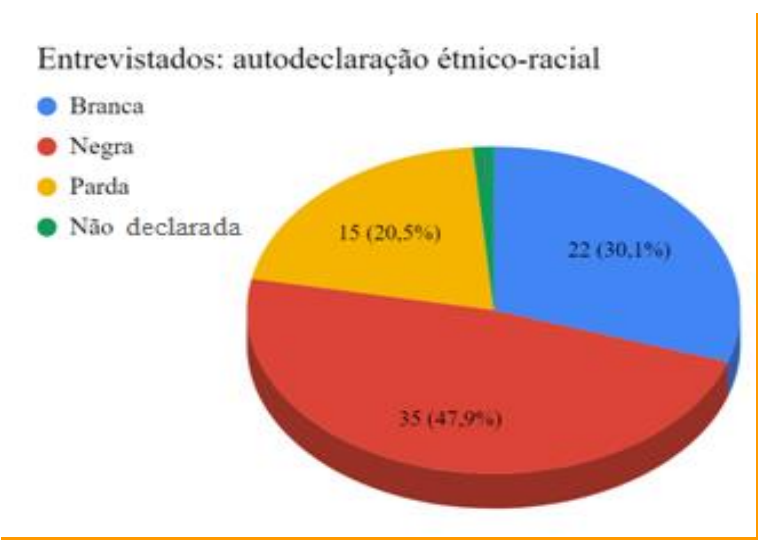

Fonte: Elaborado pelas autoras (2020). 
No que se refere à formação no nível que antecede ao ensino superior, do total de entrevistados, $50 \%$ declararam ter concluído o ensino médio em escolas públicas e 2,7\% com formação mista: entre instituições escolares públicas e privadas (Figura 4).

Figura 4 - Formação básica dos estudantes

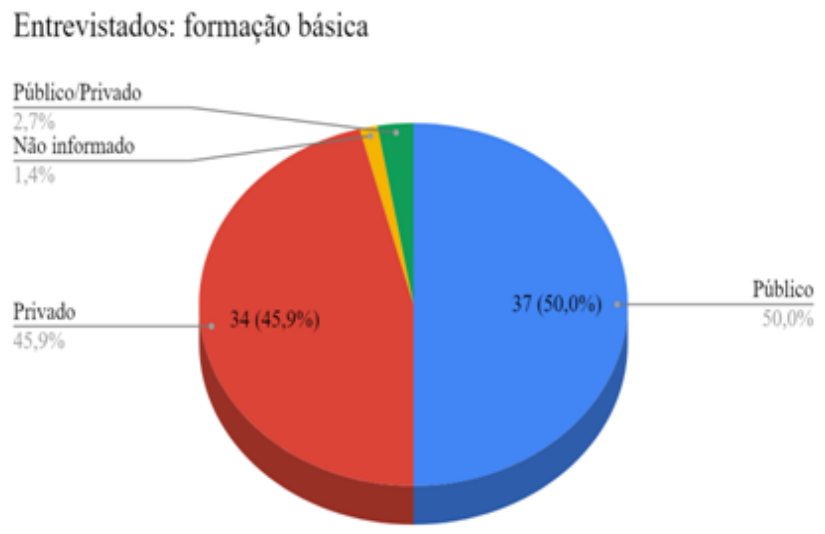

Fonte: Elaborado pelas autoras (2020).

No estudo divulgado pelo INEP em 2017, do total de estudantes de licenciaturas que realizaram o ENADE, 55,6\% ingressaram por meio da política e ações afirmativas, sendo $61,5 \%$ oriundos de escolas públicas (INEP, 2018), perfil semelhante aos estudantes entrevistados na UFBA.

Segundo Gatti et al. (2019), após a Lei n. 12.711/2012 (BRASIL, 2012), houve um aumento significativo no número de graduandos nas licenciaturas oriundos de escolas públicas, com maior representatividade das camadas majoritárias da população. Este público tem perfil familiar com menor capital cultural e pais com baixo nível de escolarização e de renda, sendo pelo menos $1 / 4$ destes oriundos de lares muito pobres, com renda familiar menor de 1,5 salário mínimo, conforme observado na fala a seguir:

Na minha família ninguém tem nível superior e, as sim, na cabeça da minha mãe, nem passava a possibilidade, nunca teve uma cobrança que eu entrasse na universidade. Então, eu estando num curso de licenciatura ou outro curso não faz nem diferença, só de estar na universidade já é uma grande conquista. (Estudante 56, Geografia, noturno).

Dados também levantados por Gatti et al. (2019) sugerem que o número de estudantes de licenciaturas negros ou pardos estão atinentes ao perfil étnico-racial da população, cuja representação é superior a 51\%. Alguns estudantes entrevistados enfatizaram a importância em acessar o ensino superior devido à possibilidade de emancipação por meio da profissionalização e de obtenção de auxílios pecuniários durante a formação. Essa emancipação é considerada 
essencial para custear suas necessidades básicas, ainda que a opção pela carreira docente não seja uma escolha vocacional, conforme relatos abaixo:

\begin{abstract}
Pra mim, é vantagem estar na universidade, qualquer curso, mesmo não sendo aquele que eu planejei. Melhor do que não estar na universidade. Enquanto pobre, negro, do interior, para mim é vantagem estar no ambiente de uma universidade, então eu vim fazer o curso. De lá até cá eu venho tentando conciliar o curso, cursei umas matérias que não são muito agradáveis por ter muito a pegada de ciências da natureza, ter muit a coisa de exatas, não é a minha área de conforto de forma alguma, é uma área desconfortante para mim porque é uma área que eu tenho uma dificuldade imensa em aprender. (Estudante 13, Ciências Naturais, diurno).

Então, todos os dias que eu vou pra escola (através do PIBID) eu consigo ter certeza que é is so que eu quero. Ou poderia ser também o contrário... eu não posso negar a questão dos 400 reais que a gente recebe da bolsa, porque eu tô aqui assistida; se eu tô aqui é porque eu tenho assistência... porque, no caso, eu moro na residência da UFBA e a gente recebe 230 que é do café da manhã e eu recebo mais 400 da bolsa. (Estudante 61, Geografia, noturno).
\end{abstract}

Para esses jovens que estão acessando a universidade a partir das políticas de cotas, o ensino superior pode representar um meio para que possam disputar oportunidades que exigem maiores qualificações. São estudantes que, em alguns casos, para conseguirem ter acesso à universidade não podem deixar de trabalhar. Portanto, a escolha pelo turno noturno por vezes é antecedente à escolha pelo curso de licenciatura, conforme visualizamos nas falas:

Na verdade, o que acontece é o seguinte: eu entrei aqui trabalhando e ainda trabalho. Como o curso noturno, que era o que eu podia fazer, era somente o de licenciatura. $\mathrm{Na}$ verdade, eu queria fazer o bacharel antes de fazer a licenciatura. (Estudante 12, física, noturno).

Porque proletariado tem que estudar de noite, por conta que tem que trabalhar de dia e à noite tem essa... quer dizer a dificuldade de poder conciliar trabalho e estudo e a facilidade também de poder conciliar os dois. Então, noturno é por conta disso. Porque... acho que todo mundo optaria se fosse... é... pelo tempo integral, ficando matutino por conta das oportunidades que são mais fáceis. (Estudante 4, Geografia noturno).

Barros (2010) argumenta que as transformações relacionadas à mediação entre experiências pessoais e vida acadêmica vivenciadas pelos jovens de classes populares podem demonstrar percursos carregados de aspirações e anseios. Desse modo, segundo Diniz-Pereira e Soares (2019), os programas de formação docente deveriam levar em consideração as experiências que seus estudantes possuem e a capacidade deles em refletir sobre essas experiências. Afirmam que a formação deveria privilegiar a participação dos estudantes nas lutas e movimentos sociais e culturais e consideram também que os futuros docentes deveriam chegar nos cursos de formação com a percepção de que há falhas na sociedade, no que tange à justiça e à igualdade.

Assim, para Moehlecke (2004), as políticas de ações afirmativas possuem caráter social, já que favorecem a igualdade de oportunidades, colocando os indivíduos em condições 
igualitárias, cujo objetivo é incentivar o acesso a meios dignos de vida, como educação e trabalho, a grupos minoritários nas estruturas de poder e dominação. Os estudantes mencionaram o acesso ao ensino superior por parte de um grupo que sofre exclusão:

Pra mim, que vim de uma família que não chegou nem ao ensino médio, é de peso estar ocupando um espaço como esse no centro de produção de conhecimento. $\mathrm{O}$ sentimento é de gratidão, ao mes mo tempo a percepção de que é necessário continuar, é um espaço que tem que ser ocupado pela gente, por pessoas que sofrem a exclusão social. (Estudante 68, História, noturno)

Porque estar no curso noturno de his tória, no atual momento político do país, é um ato de resistência, é um ato político. Então, eu mesma moro em bairro periférico, pego ônibus às dezda noite todos os dias. Então, eu sendo mulher, preta, morando em bairro periférico pegando ônibus às dez horas?! É um ato político! Não deixa de ser... Mas eu tô aqui, né? Tô aqui pra tentar fazer a diferença, mesmo com todas as limitações . (Estudante 65, His tória, noturno).

Colocando questões de justiça social, ao utilizar o termo status social, compreende-se que as necessidades por reconhecimento de atores subordinados diferem daquelas dos socialmente privilegiados, conforme podemos observar na fala dessa estudante de história.

\section{Atores sociais no engajamento pela educação de qualidade no Brasil}

A necessidade de reconhecimento pode refletir na formação dos futuros professores fazendo com passem a "contribuir para a diminuição das desigualdades existentes entre crianças das classes trabalhadoras, média e alta nos sistemas de escola pública de todo o mundo" (MARCONDES, 2008, p. 1), constituindo-se em educadores ativistas críticos engajados, que se recusam a aceitar uma educação que não seja inclusiva e que também não direcione para "uma nova política de voz e reconhecimento na educação" (APPLE, 2017, p. 905). Os relatos de alguns estudantes coincidiram com essa perspectiva:

\footnotetext{
A minha expectativa é mudar a realidade desses alunos... Nenhum deles quer fazer universidade, parece brincadeira, mas eu já ouvi várias vezes que a gente tava perdendo nosso tempo lá, porque eles querem ser ladrão. Então... Eu quero muito tentar mudar isso. (Estudante 61, Geografia, noturno)

Eu vejo problemas até na universidade; você tem uma exclusão dentro da universidade. É uma cor que tá ocupando os espaços de representação, é um gênero que ocupa os espaços de representação, então são problemas que tornam como necessidade a discussão dos direitos humanos. E é até válido, porque se eu, como professor, vou formar um cidadão, um ser humano crítico, eu tenho que trabalhar direitos humanos. É de fundamental importância pra minha formação, tanto pra mim quanto pra pessoa que eu vou formar. (Estudante 68, História, noturno).
}

Como podemos observar na reflexão do estudante, toda prática educativa é também uma prática política (FREIRE, 2003), sendo fundamental discutir a formação docente na perspectiva de uma educação emancipatória. Refletir sobre o fazer docente é uma condição política e fundamental desta formação, desde que ela se vincule à promoção da justiça social e intelectual 
(FONTOURA, 2017). Assim, o processo educativo é valorizado pelos estudantes de licenciatura, ao considerarem que:

A educação é a solução de tudo. E querendo ou não, apes ar de ser clichê, tudo bem, é um clichê verdadeiro, é um estereótipo que realmente condiz com a realidade. (Estudante 46, Letras, noturno)

[...] é necessário a gente refletir, porque eu acredito que a educação é base pra qualquer conquista. Muitas pessoas perdem oportunidades de melhorar de vida e conseguir lutar por direitos; as pessoas não fazem isso por não saberem que podem fazer is so. E eu acho que a educação é a principal porta pra is so. Quando você tem um estímulo ao conhecimento, à leitura, você vai buscar informação em qualquer lugar. Então a gente tem que estar lutando pra que cada vez mais jovens estejam estudando, cada vez mais crianças estejam na es cola, cada vez mais adultos, que não tiveram essa oportunidade quando crianças, queiram voltar pra escola. (Estudante 71, Letras, diurno).

Tendo como finalidade a educação emancipatória, torna-se essencial, nos cursos de licenciatura, haver espaços de reflexão acerca da formação de subjetividade integral das pessoas, tanto a partir do autoconhecimento como do reconhecimento do outro. Assim, para que uma instituição educacional formadora "contribua para transformar a sociedade, para fazêla mais justa, é necessário ensinar justiça social e que seja ela mesma socialmente mais justa" (MURILLO, 2019, p. 79, tradução nossa). Trata-se de uma questão de ética.

Essa percepção reflete a compreensão de que, em um processo de formação, mais importante do que notas, frequência e outras formas de mensuração da avaliação do estudante, são as relações intersubjetivas alinhadas à prática reflexiva do ser docente, que o conduzirá a uma nova concepção do fazer pedagógico como um processo em sua historicidade, que reconheça suas implicações com a realidade vivenciada e complexa (MARTINS, 2014).

Alguns estudantes demonstraram as mudanças que foram proporcionadas em seu modo de pensar, em decorrência da entrada na universidade:

\footnotetext{
No início quando lhe respondi sobre etnia eu te disse que sou negra, eu digo que sou negra agora, depois que virei estudante. Mais de 50 anos, agora que virei estudante de Letras da UFBA. Que até então eu era parda, me considerava parda, meus documentos todos estão pardo, porque é cor da minha pele, mas agora eu tenho consciência de que ser negra não é só a cor da pele. E eu aprendi aqui, confesso, aprendi de uma forma científica, porque antes eu tinha uma noção, mas não sabia ao certo, não tinha clareza. (Estudante 11, Letras, diurno).

[...] quando o IBGE foi lá em casa, era todo mundo pardo. E é isso, quanto mais claro... Era um racismo que, por eu não estudar, por eu não saber, pra mim não era racismo, eu era realmente parda. E quando entrei no projeto 'mulheres negras', eu percebi que eu era negra. Quando eu entrei aqui na UFBA eu entrei nesse projeto e comecei a estudar, principalmente as declarações que o IBGE usa né, que é o pardo, negro... Hoje eu não concordo mais com essa cor pardo, eu acho que não existe, não consigo definir uma pessoa parda (Estudante 61, Geografia, noturno).
}

Posicionamento como esses podem significar indicativos de que a afiliação estudantil colabora para o processo de autoconhecimento e fortalecimento social. A fala dos estudantes 
não deixa claro se esse processo se deu especificamente no curso de licenciatura ou se eles participaram de outras matérias ou cursos extracurriculares. No entanto, o que se percebe é que estar na universidade contribuiu para esses(as) estudantes compreenderem, avaliarem e afirmarem os significados socialmente construídos acerca deles(as) mesmos. Esse movimento de transformação contribui para a aproximação entre professor, estudante e comunidade (GIROUX, 1997).

\title{
3 A hierarquização dos saberes popular e científico na Universidade
}

Para Giroux (1997), um dos principais problemas nos cursos de formação de professores é a falta de ênfase nos currículos sobre as relações de poder e sua distribuição hierárquica, como também no estudo da teoria social crítica. Ao se enfatizar mais os aspectos metodológicos e mensuráveis da aprendizagem, as questões referentes à natureza do poder, ideologia e cultura (que produzem formas particulares de experiência estudantil) passam a ser negligenciadas e não discutidas na formação do professor. Isso é notório na fala do estudante de Pedagogia, que trabalha com educação popular:

\begin{abstract}
Eu trabalho como educador popular, em ONGs, bibliotecas, em espaços não formais de contexto escolar... Eu venho de uma linha de educação popular. Então, como dentro da linha da educação popular, a gente se prepara mais dentro da parte das lutas sociais, das lutas cotidianas e da criação e de alternativas, quer dizer, mais junto com o povo. Então aqui, como eu dentro da minha perspectiva de educação popular, acho que (a universidade) não me forma professor. (Estudante 62, Pedagogia, diurno).
\end{abstract}

A educação popular pode ser conceituada como práticas político-pedagógicas que possibilitam a inserção das classes populares e criação de metodologias e referenciais teóricos de inclusão social e respeito às diversidades culturais (FREIRE, 2003). O representante no Brasil dessa perspectiva é Paulo Freire, que desenvolveu seu trabalho com práticas de resistência ao modelo formal de educação, criticando a sociedade instituída a partir da política (contestação da estrutura social opressora), da ética (valorização, dignidade e libertação do ser humano), metodologia (estratégias alternativas à pedagogia tradicional) e epistemologia (por utilizar o diálogo para parâmetros de elaboração, sistematização e avaliação do conhecimento).

Monfredini e Mora (2018) defendem que a razão neoliberal contribuiu para ampliar o distanciamento entre universidade e classes populares, ou seja, a ciência e o conhecimento popular. Porém, Santos (2011) defende que o processo de mobilização social pode retomar a atuação militante na universidade em prol de aproximar a cultura popular da científica.

De tal modo, é necessário, para Santos e Meneses (2009), a construção e validação do conhecimento nascido nos grupos e movimentos sociais como uma forma de resistência contra as injustiças e as opressões sistemáticas que são causadas pelo capitalismo, colonialismo e 
patriarcado. Por meio de conexões translocais, esse tipo de conhecimento pode ter seu potencial emancipatório maximizado. Outrossim, Santos (2011) considera a universidade um espaço profícuo que possibilita a troca de conhecimentos (científico e não científico).

\section{Considerações finais}

Mediante a análise aqui realizada, observa-se que o perfil dos 74 estudantes de licenciatura da UFBA, participantes da pesquisa, aponta para maioria negra e parda, oriunda de escola pública, com renda familiar entre 1 e 3 salários mínimos, sendo 28 benefic iários das cotas raciais e sociais. Ficou claro que alguns estudantes escolheram o curso de licenciatura (principalmente no turno noturno) por ser a opção mais acessível, considerando-se a nota no Exame Nacional de Ensino Médio (ENEM) ou pela facilidade de inserção no mercado de trabalho. Percebemos, portanto, que as ações afirmativas são de suma importância para viabilizar maior inclusão e democratização do acesso, mas ainda é insuficiente para diminuir os abismos sociais, políticos e econômicos existentes no país, cujos reflexos são percebidos nos sistemas educacionais.

Apesar de a Universidade ser um espaço promotor de reflexão para formação da identidade própria dos estudantes, conforme foi observado em relatos, ainda há uma dificuldade em validar as questões de exclusão e discriminação no processo formativo dos professores. Um dos fatores que implicam diretamente nessa questão são as ações para a permanência desses estudantes no ambiente universitário, que ainda são muito escassas, pois do total de estudantes cotistas, apenas 6 recebem algum tipo de assistência estudantil. Os conhecimentos prévios adquiridos também poderiam servir como um caminho para o processo de educação emancipatória nos cursos de formação de professores.

Assim, apontamos essa demanda urgente, por parte dos próprios estudantes, para validar esse tipo de conhecimento necessário para esses profissionais. Refletindo com base na concepção geopolítica do conhecimento, percebe-se que a universidade ainda se mantém validando os saberes eurocêntricos como o único legítimo para ser compartilhado no ensino superior. No entanto, os estudantes, ao perceberem sua presença como um fator de resistência nesse espaço, também destacam a existência de hierarquia dos conhecimentos e a dificuldade de buscar uma perspectiva libertadora que vise facilitar a compreensão de nós mesmos, depois de séculos de submissão e alienação.

Mesmo assim, a formação de professores pode ser considerada um fértil reduto de esperança e de atuação quando se pretende alterar os sistemas educativos, no sentido de eles 
corresponderem mais eficazmente à Equidade e à Inclusão, tanto quanto aos conhecimentos previamente adquiridos dos estudantes que acessam esses cursos.

\section{Referências}

ALMEIDA FILHO, N. et al. Ações afirmativas na universidade pública: o caso da UFBA. Salvador: Centro de Estudos Afro-Orientais, 2005.

APPLE, M. W. A luta pela democracia na educação crítica. Revista e-Curriculum, São Paulo, v. 15, n. 4, p. 894-926, 2017. DOI: http://dx.doi.org/10.23925/1809-3876.2017v15i4p894-926. Disponível em: https://revistas.pucsp.br/curriculum/article/view/35530. Acesso em: 12 abr. 2019.

BARDIN, L. Análise de conteúdo. Ed. rev. e ampl. São Paulo: Edições 70, 2016.

BARROS, M. M. L. de. Trajetórias de jovens adultos: ciclo de vida e mobilidade social. Horizontes Antropológicos, Porto Alegre, v. 16, n. 34, p. 71-92, 2010. DOI: https://doi.org/10.1590/S010471832010000200004. Disponível em: https://www.scielo.br/pdf/ha/v16n34/04.pdf. Acesso em: 12 abr. 2019.

BOBBIO, N. A era dos direitos. Trad. Carlos Nelson Coutinho. Rio de Janeiro: Elsevier, 2004.

BRASIL. Presidência da República. Lei $n^{\circ} 12.711$, de 29 de agosto de 2012. Dispõe sobre o ingresso nas universidades federais e nas instituições federais de ensino técnico de nível médio e dá outras providências. Disponível em: http:/www.planalto.gov.br/ccivil_03/_ato20112014/2012/lei/112711.htm. Acesso em: 20 ago. 2019.

DINIZ-PEREIRA, J. E.; SOARES, L. J. G. Formação de Educadoras/es, diversidade e compromisso social. Educ. rev., Belo Horizonte, v. 35, e217314, 2019. ISSN 1982-6621. DOI:

https://doi.org/10.1590/0102-4698217314. Disponível em: https://www.scielo.br/pdf/edur/v35/19826621-edur-35-e217314.pdf. Acesso em: 29 jul. 2019.

FONTOURA, H. A. da. Formação de professores para a justiça social: uma reflexão sobre a docência na residência pedagógica. Revista Ibero-Americana de Estudos em Educação, Araraquara, v. 12 n. 1, p.120-133, 2017. e-ISSN: 1982-5587. DOI: https//doi.org/10.21723/riaee.v12.n1.7932. Disponível em: https $/ /$ periodicos.fclar.unesp.br/iberoamericana/article/view/7932/6255. Acesso em: 29 jul. 2019.

FREIRE, P. El grito manso. Buenos Aires: Siglo XIX Editores Argentina, 2003.

GATTI, B. A. Educação, escola e formação de professores: políticas e impasses. Educar em Revista, Curitiba, n. 50, p. 51-67, out./dez. 2013. Disponível em: https://www.scielo.br/pdf/er/n50/n50a05.pdf. Acesso em: 13 abr. 2019.

GATTI, B. A. et al. Professores do Brasil: novos cenários de formação. Brasîlia: UNESCO, 2019.

GIROUX, H. Os professores como intelectuais. Rumo à uma pedagogia crítica da aprendizagem. Porto Alegre: Artes Médicas, 1997.

INEP. Enade 2017: resultados e indicadores. Disponível em: http://portal.mec.gov.br/docman/outubro2018-pdf-1/98271-2018-10-09-apresentacao-resultados-enade-2017-2018-10-09/file. Acesso em: 10 set. 2019. 
KRISHA, K.; TARASOV, A. Affirmative action: one size does not fit all. Cambridge: National Bureau of Economic Research, 2013.

LAPO, F. R.; BUENO, B. O. Professores, desencanto com a profissão e abandono do magistério. Cad. Pesqui. [online], São Paulo, n. 118, p. 65-88, 2003. ISSN 1980-5314. DOI: https://doi.org/10.1590/S0100-15742003000100004. Disponível em: https://www.scielo.br/pdf/cp/n118/16830.pdf. Acesso em: 26 jul. 2019.

LIBÂNEO, J. C. Adeus professor, adeus professora? Novas exigências educacionais e profissão docente. 13 ed. São Paulo: Cortez, 2011. (Coleção Questões da Nossa Época).

LOPES, A. D. Affirmative action in Brazil: how students' field of study choice reproduces social inequalities. Journal Studies in Higher Education, v. 42, n. 12, p. 2343-2359, 2017. DOI: https://doi.org/10.1080/03075079.2016.1144180. Disponível em: https://www.tandfonline.com/doi/full/10.1080/03075079.2016.1144180?scroll=top\&neeneedAcc=true . Acesso em: 25 jul. 2019.

MAINARDES, J.; MARCONDES, M. I. Entrevista com Stephen J. Ball: um diálogo sobre justiça social, pesquisa e política educacional. Educ. Soc., Campinas, v. 30, n. 106, p. 303-318, jan./abr. 2009. DOI: 10.1590/S0101-73302009000100015. Disponível em: http://www.scielo.br/pdf/es/v30n106/v30n106a15.pdf. Acesso em: 24 set. 2019.

MARCONDES, M. I. Justiça social e formação de professores. Educ. Soc. Campinas, v. 29, n. 105, p. 1250-1254, 2008. Disponível em http://www.scielo.br/scielo.php?script=sci_arttext\&pid=S0101$73302008000400016 \& \operatorname{lng}=e n \& n r m=$ iso. Acesso em: 29 jul. 2019.

MARTINS, J. B. A formação de professores no âmbito da abordagem multirreferencial. Psicol. Esc. Educ., Maringá, v. 18 n. 3, 2014. v. 18, n. 3, p. 467-476, 2014. DOI: https $/ /$ doi.org/10.1590/21753539/2014/0183768. Disponível em: https://www.scielo.br/pdf/pee/v18n3/1413-8557-pee-18-030467.pdf. Acesso em: 18 fev. 2020.

MIGLIEVICH-RIBEIRO, A.; ROMERA JR. E. Geopolítica do conhecimento e descolonização epistemológica em Darcy Ribeiro. Revista Interinstitucional Artes de Educar. Rio de Janeiro, v. 3 n. 2,

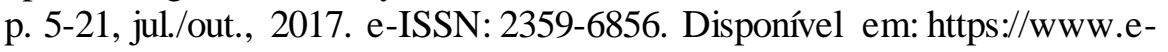
publicacoes.uerj.br/index.php/riae/article/view/31705/22436. Acesso em: 12 mai. 2020.

MIGNOLO, W. D. The ideia of Latin America. Victoria: Blackwell Publishing, 2005.

MIGNOLO, W. D. Desobediência epistêmica: a opção descolonial e o significado de identidade em política. Cadernos de Letras da UFF - Dossiê: Literatura, língua e identidade, Niterói, n. 34, p. 287324, 2008. ISSN (online) 2447-4207. Disponível em: http://www.cadernosdeletras.uff.br/joomla/images/stories/edicoes/34/traducao.pdf. Acesso em: 12 mai. 2020.

MIGNOLO, W. D. The decolonial option. In: MIGNOLO, W. D.; WALSH, C. E. On decoloniality: concepts, analytics, praxis. Durham and London: Duke University Press, 2018.

MOEHLECKE, S. Ação afirmativa no ensino superior: entre a excelência e a justiça social. Educ. Soc., Campinas, v. 25, n. 88, p. 757-776, Especial - Out. 2004. ISSN 1678-4626. https://doi.org/10.1590/S0101-73302004000300006. Disponível em: https://www.scielo.br/pdf/es/v25n88/a06v2588.pdf. Acesso em: 05 mai. 2020.

MONFREDINI, I.; MORA, R. P. Poder, geopolítica e mobilização do conhecimento: a universidade em questão. Revista Triângulo, Uberaba, v. 11, n. 4-esp., p.150-167, 2018. ISSN 2175-1609.

Disponível em: 
http://seer.uftm.edu.br/revistaeletronica/index.php/revistatriangulo/artic le/download/3453/33. Acesso em: 12 mai. 2020.

MORGADO, J. C. O estudo de caso na investigação em educação. Santo Tirso: De facto editores, 2018.

MURILLO, F. J. Construyendo escuelas socialmente justas para transformar el mundo. Ruta Maestra, v. 27, p. 77-80. 2019. Disponível em: https://rutamaestra.santillana.com.co/wpcontent/uploads/2019/10/Construyendo-escuelas-socialmente-justas-para-transformar-el-mundo.pdf. Acesso em: 10 abr. 2020.

PAULA, M. de F. de. As propostas de democratização do acesso ao ensino superior do governo Lula: reflexões para o debate. Avaliação: Revista da Avaliação da Educação Superior, v. 11, n. 1, p. 133147, 2006. Disponível em: http://periodicos.uniso.br/ojs/index.php/avaliacao/article/view/925. Acesso em: 27 ago. 2019.

RAWLS, J. A theory of justice. Cambridge, MA: Harvard University Press, 1999.

SANTOS, B. S. A universidade no século XXI: por uma reforma democrática e emancipatória da universidade. São Paulo: Cortez, 2011.

SANTOS, B. S.; MENESES, M. P. Epistemologias do Sul. Coimbra: Almedina S.A., 2009.

SEN, A. The idea of justice. London: Allen Lane, 2009.

ZEICHNER, K. M. Uma análise crítica sobre uma "reflexão" como conceito estruturante na formação docente. Educ. Soc., Campinas, v. 29, n. 103, p. 535-554, maio/ago. 2008. Disponível em https://www.scielo.br/pdf/es/v29n103/12.pdf. Acesso em: 29 jul. 2019. DOI:

http://dx.doi. org/10.1590/S0101-73302008000200012. 